\title{
Rethinking maps
}

\section{Rob Kitchin ${ }^{*}$ and Martin Dodge ${ }^{2}$}

\author{
'NIRSA and Department of Geography, National University of Ireland, \\ Maynooth, Co. Kildare, Ireland \\ 2Department of Geography University of Manchester, UK
}

\begin{abstract}
In this paper we argue that cartography is profitably conceived as a processual, rather than representational, science. Building on recent analysis concerning the philosophical underpinnings of cartography we question the ontological security of maps, contending that it is productive to rethink cartography as ontogenetic in nature; that is maps emerge through practices and have no secure ontological status. Drawing on the concepts of transduction and technicity we contend that maps are of-the-moment, brought into being through practices (embodied, social, technical); that mapping is a process of constant reterritorialization. Maps are never fully formed and their work is never complete. Maps are transitory and fleeting, being contingent, relational and context-dependent; they are always mappings; spatial practices enacted to solve relational problems (eg, how best to create a spatial representation, how to understand a spatial distribution, how to get between $A$ and $B$, and so on). Such a rethinking, we contend, provides a fresh perspective on cartographic epistemology, and could work to provide a common framework for those who undertake mapping as applied knowledge (asking technical questions) and those that seek to critique such mapping as a form of power/knowledge (asking ideological questions). We illustrate our argument through an analysis of mapping practices.
\end{abstract}

Key words: cartography, maps, ontogenesis, ontology, practice.

\section{Cartography's ontological crisis}

Maps have long been seen as objective, neutral products of science. Cartography is the means by which the surface of the earth is represented as faithfully as possible. The skill of the cartographer is to capture and portray relevant features accurately. Cartography as an academic and scientific pursuit then largely consists of theorizing how best to represent spatial data (through new devices, eg, choropleth maps, contour lines; through the use of colour; through ways that match how people think, eg, drawing on cognitive science; and so on). In the latter part of the twentieth century, the science of cartography was influenced deeply by Arthur Robinson. He recast cartography, focusing in particular on systematically detailing map design principles with the map user in mind. His aim was to produce what he termed 'map effectiveness' - that is, maps that capture and portray relevant information in away that the map reader can analyse and interpret (Robinson et al., 1995). Since the mid-1980s this particular view of cartography has been

*Author for correspondence. Email: rob.kitchin@nuim.ie 
under challenge. On the one side have been other 'scientific' cartographers seeking to replace Robinson's model with one more rooted in cognitive science (eg, MacEachren, 1995) or visualization principles (eg, Antle and Klickenberg, 1999); on the other have been critical cartographers who, drawing on critical social theory, have questioned the rationale and principles of cartography, but often have little say about the technical aspects of how to create a map or how maps work (Crampton, 2003).

Focusing on the latter, in his now classic analysis, Brian Harley (1989) drew on the ideas of Michel Foucault and Jacques Derrida to argue that the process of mapping was not a neutral, objective pursuit but rather was one laden with power. He contended that the process of mapping consists of creating, rather than simply revealing, knowledge. In the process of creation many subjective decisions are made about what to include, how the map will look, and what the map is seeking to communicate (MacEachren, 1995; Monmonier, 1995). As such, Harley noted, maps are imbued with the values and judgements of the individuals who construct them and they are undeniably a reflection of the culture in which those individuals live. Maps are thus the product of privileged and formalized knowledges and they also produce knowledge about the world. And, in this sense, maps are the products of power and they produce power. In contrast to the scientific view that positions maps in essentialist terms, Harley cast maps as social constructions; as expressions of power/ knowledge. Others, such as Denis Wood (1992), Mark Monmonier (1995) John Pickles (2004), and ourselves (Dodge and Kitchin, 2000) have extensively demonstrated this power/knowledge revealing the ideology inherent in maps (or their 'second text') and how maps 'lie' (or at least provide selective stories) due to the choices and decisions that have to be made during their creation, and through how they are read by users.

In the 1990s, similar criticisms were levelled at geographical information systems (GIS). In the provocative book Ground truth (Pickles, 1995), a number of authors applied Harley's ideas to GIS to argue that the 'positivistic' claims of GIScience were hollow; that despite the claims to 'god-like' positionality and the neutrality of products GIS was a situated and valued-laden pursuit. In combination, the application of critical theory to cartography and GIS has produced the fields of 'critical cartography' and 'critical GIS', respectively (see Harris and Harrower, 2006).

As Denis Wood (1993) and Jeremy Crampton (2003) outline, however, Harley's application of Foucault to cartography, and therefore nearly all critical cartography that follows, is limited. Harley's observations, while opening a new view onto cartography, stopped short of following Foucault's line of inquiry to its logical conclusion. Instead, Crampton argues that Harley's writings 'remained mired in the modernist conception of maps as documents charged with 'confessing' the truth of the landscape' (p. 7). In other words, Harley believed that the truth of the landscape could still be revealed if we took account of the ideology inherent in the representation. The problem was not the map per se, but 'the bad things people did with maps' (Wood, 1993: 50, original emphasis). Harley's strategy was to identify the politics of representation in order to circumnavigate them (to reveal the truth lurking underneath), not fully appreciating, as with Foucault's observations, that there is no escaping the entangling of power/knowledge. Another strategy to address the crisis of representation has been the production and valuing of countermappings - maps made by diverse interests that provide alternative viewpoints to state-sanctioned and commercial cartography (Wood, 1992). Again, this strategy does not challenge the ontological status of the map; rather it simply reveals the politics of mapping.

Crampton's (2003) solution to the limitations of Harley's and Wood's strategies is to extend the use of Foucault and to draw on the ideas of Heidegger and other critical cartographers such as Edney. In short, Crampton 
outlines a 'non-confessional understanding of spatial representation' wherein maps instead of 'being interpreted as objects at a distance from the world, regarding that world from nowhere, that they be understood as being in the world, as open to the disclosure of things' (p. 7). Such a shift, Crampton argues, necessitates a move from understanding cartography as a set of ontic knowledges to examining its ontological terms. Ontic knowledge consists of the examination of how a topic should proceed from within its own framework where the ontological assumptions about how the world can be known and measured are implicitly secure and beyond doubt (Crampton, 2003). In other words, there is a core foundational knowledge - a taken for granted ontology that unquestioningly underpins ontic knowledge. With respect to cartography this foundational ontology is that the world can be objectively and truthfully mapped using scientific techniques that capture and display spatial information. Cartography in these terms is purely technical and develops by asking selfreferential, methodological questions of itself that aim to refine and improve how maps are designed and communicate. (Crampton, 2003, gives the examples of what colour scheme to use, the effects of scale, how maps are used historically and politically.) In these terms a book like Robinson et al. (1995) is a technical manual that does not question the ontological assumptions of the form of mapping advocated; rather it is a 'how to do 'proper' cartography' book that in itself perpetuates the security of cartography's ontic knowledge. In this sense, Harley's questioning of maps is also ontical (see Harley, 1992), as his project sought to highlight the ideology inherent in maps (and thus expose the truth hidden underneath) rather than to question the project of mapping per se; 'it provided an epistemological avenue into the map, but still left open the question of the ontology of the map' (Crampton, 2003: 90). In contrast, Crampton details that examining cartography ontologically consists of questioning the project of cartography itself.
Such a view leads Crampton, following Edney (1993), to argue for the development of a non-progressivist history of cartography; the development of a historical ontology that rather than being teleological (wherein a monolithic view of the history of cartographic practices is adopted that sees cartography on a single path leading to more and more complete, accurate and 'truthful' maps) is contingent and relational (wherein mapping - and truth - is seen as contingent on the social, cultural and technical relations at particular times and places). Maps from this perspective are historical products operating within 'a certain horizon of possibilities' (Crampton, 2003: 51). It thus follows that maps created in the present are products of the here-and-now, no better than maps of previous generations, simply different to them. Defining a map then is dependent on where and when the map was created, and where and when it was engaged with, as what a map is and the work that it does in the world has changed over time (see also Livingstone, 1992; 2005). For Crampton (2003) this means that a politics of mapping should move beyond a 'critique of existing maps' to consist of 'a more sweeping project of examining and breaking through the boundaries on how maps are, and our projects and practices with them' (p. 51): it is about exploring the 'being of maps'; how maps are conceptually framed in order to make sense of the world.

Similarly, John Pickles (2004) seeks to extend Harley's observations beyond ontic status, focusing on 'the work that maps do, how they act to shape our understanding of the world, and how they code that world' ( $p$. 12). Pickles' project is to chart the 'practices, institutions and discourses' of maps and their social roles within historical, social and political contexts from within a poststructural framework that understands maps as complex, multivocal and contested, and which rejects the notion of some 'truth' that can be uncovered by exposing ideological intent. Pickles' detailed argument unpicks the science of representation, calling for a 
postrepresentational cartography that understands maps not as mirrors of nature, but as producers of nature. To paraphrase Heisenberg (1959, cited in Pickles, 2004), Pickles argues that cartography does not simply describe and explain the world; it is part of the interplay between the world and ourselves; it describes the world as exposed to our method of questioning. In this sense, a map is not a representation of the world but an inscription that does (or sometimes does not do) work in the world' (Pickles, 2004: 67). Thus ' $\mathrm{m}$ ] aps provide the very conditions of possibility for the worlds we inhabit and the subjects we become . . . They have literally and figuratively over-coded and overdetermined the worlds in which we live... Maps and mapping precede the territory they "represent" " (p. 5); they do not 'simply represent territory, but are understood as producing it' (Pickles, 2004: 146). For Pickles, maps work neither denotatively (shaped by the cartographic representation, labelling, interbedded with other material such as explanatory text, etc) or connotatively (what the mapper brings to the representation in terms of skills, knowledges, etc) but as a fusion of the two. Pickles thus proposes a hermeneutic approach that interprets maps as problematic texts, texts that are not authored or read in simple ways. Rather than a determinate reading of the power of maps that seeks to uncover in a literal sense the authorial and ideological intent of a map (who made the map and for what purpose), Pickles expresses caution in fixing responsibility in such a manner, recognizing the multiple, institutional and contextual nature of mapping. Similarly, the power of maps as actants in the world (as entities that have effects) is seen as diffuse, reliant on actors embedded in contexts to mobilize their potential effects:

All texts are ... embedded within chains of signification: meaning is dialogic, polyphonic and multivocal - open to, and demanding of us, a process of ceaseless contextualization and recontextualization. (Pickles, 2004: 174)
Alongside a hermeneutic analysis of maps, Pickles proposes that a postrepresentational cartography consists of the writing of denaturalized histories of cartography and the production of de-ontologized cartography. Denaturalized histories reveal the historicizing and contextualizing conditions that have shaped cartographic practices, to:

explore the ways in which particular machines, disciplines, styles of reasoning, conceptual systems, bodies of knowledge, social actors of different scales.... and so forth, have been aligned at particular times and particular places. (Pickering, 1995, cited in Pickles, 2004: 70)

In other words, they consist of genealogies of how cartography has been naturalized and institutionalized across space and time as particular forms of scientific practices and knowledges. A de-ontologized cartography is on the one hand about accepting countermappings as having equal ontological status as scientific cartographic (that there are many valid, cartographic ontologies) and, on the other, deconstructing, reading differently, and reconfiguring scientific cartography (to examine alternative and new forms of mapping).

While we think Crampton's and Pickles' ideas are very useful, and we are sympathetic to their projects, we are troubled by the ontological security the map still enjoys within their analysis. Despite the call for seeing maps as 'beings in the world', as non-confessional spatial representations, postrepresentational or de-ontologized cartography, and nonprogressivist or denaturalized histories of cartography, maps within Crampton and Pickles' view remain secure as spatial representations that say something about spatial relations in the world (or elsewhere). The map might be seen as diverse, rhetorical, relational, multivocal and having effects in the world, but is nonetheless a coherent, stable product $-a$ map. While in some respects Crampton and Pickles demonstrate that maps are not, in Latour's (1989) terms, immutable mobiles (that is, stable and transferable forms of knowledge that allow them to be portable 
across space and time), they nonetheless slip back into that positioning, albeit with maps understood as complex, rhetorical devices not simply representations. In this sense, Figure 1 is unquestioningly a map.

We think it productive to take a different tack to think ontologically about cartography. For us, maps, as we illustrate in the next section and explain theoretically in the following section, have no ontological security, they are ontogenetic in nature. Maps are of-themoment, brought into being through practices (embodied, social, technical), always remade every time they are engaged with; mapping is a process of constant reterritorialization. As such, maps are transitory and fleeting, being contingent, relational and context-dependent. Maps are practices - they are always mappings; spatial practices enacted to solve relational problems (eg, how best to create a spatial representation, how to understand a spatial distribution, how to get between $A$ and $B$, and so on). From this position, Figure 1 is not unquestioningly a map (an objective, scientific representation (Robinson) or an ideologically laden representation (Harley), or an inscription that does work in the world (Pickles)), it is rather a set of points, lines and colours that takes form as, and is understood as, a map through mapping practices (an inscription in a constant state of reinscription). Without these practices a spatial representation is simply coloured ink on a page. (This is not a facetious statement without the knowledge of what constitutes a map is or how a map works how can it be otherwise?) Practices based on learned knowledge and skills (re)make the ink into a map and this occurs every time they are engaged with - the set of points, lines and areas is recognized as a map; it is interpreted, translated and made to do work in the work. As such, maps are constantly in a state of becoming; constantly being remade.

At the heart of our analysis are two fundamental questions. First, how do individuals know that an arrangement of points, lines and colours constitute a map (rather than a landscape painting or an advertising poster)? How does the idea of a map and what is understood as a map gain ontological security and gain the semblance of an immutable mobile? Our thesis is that ontological security is maintained because the knowledge underpinning cartography and map use is learned and constantly reaffirmed. A map is never a map with ontological security assumed; it is brought into the world and made to do work through practices such as recognizing, interpreting, translating, communicating, and so on. It does not re-present the world or make the world (by shaping how we think about the world), it is a co-constitutive production between inscription, individual and world; a production that is constantly in motion, always seeking to appear ontologically secure. Second, how do maps become? How does the constant, co-constitutive production of a map occur? We seek to answer this question by examining two vignettes outlining the unfolding nature of mapping and by drawing on the concepts of transduction (that understands the unfolding of everyday life as sets of practices that seek to solve ongoing relational problems) and technicity (the power of technologies to help solve those problems) (see Dodge and Kitchin, 2005).

The argument we forward is not being made to demonstrate clever word play or to partake in aimless philosophizing. ${ }^{1}$ In contrast, we are outlining what we believe is a significant conceptual shift in how to think about maps and cartography (and, by implication, what are commonly understood as other representational outputs and endeavours); that is a shift from ontology (how things are) to ontogenesis (how things become) - from (secure) representation to (unfolding) practice. This is not minor argument with little theoretical or practical implications. Rather it involves adopting a radically different view of maps and cartography. In particular, we feel that the ontological move we detail has value for five reasons. First, we think it is a productive way to think about the world, including cartography. It acknowledges how life unfolds in 


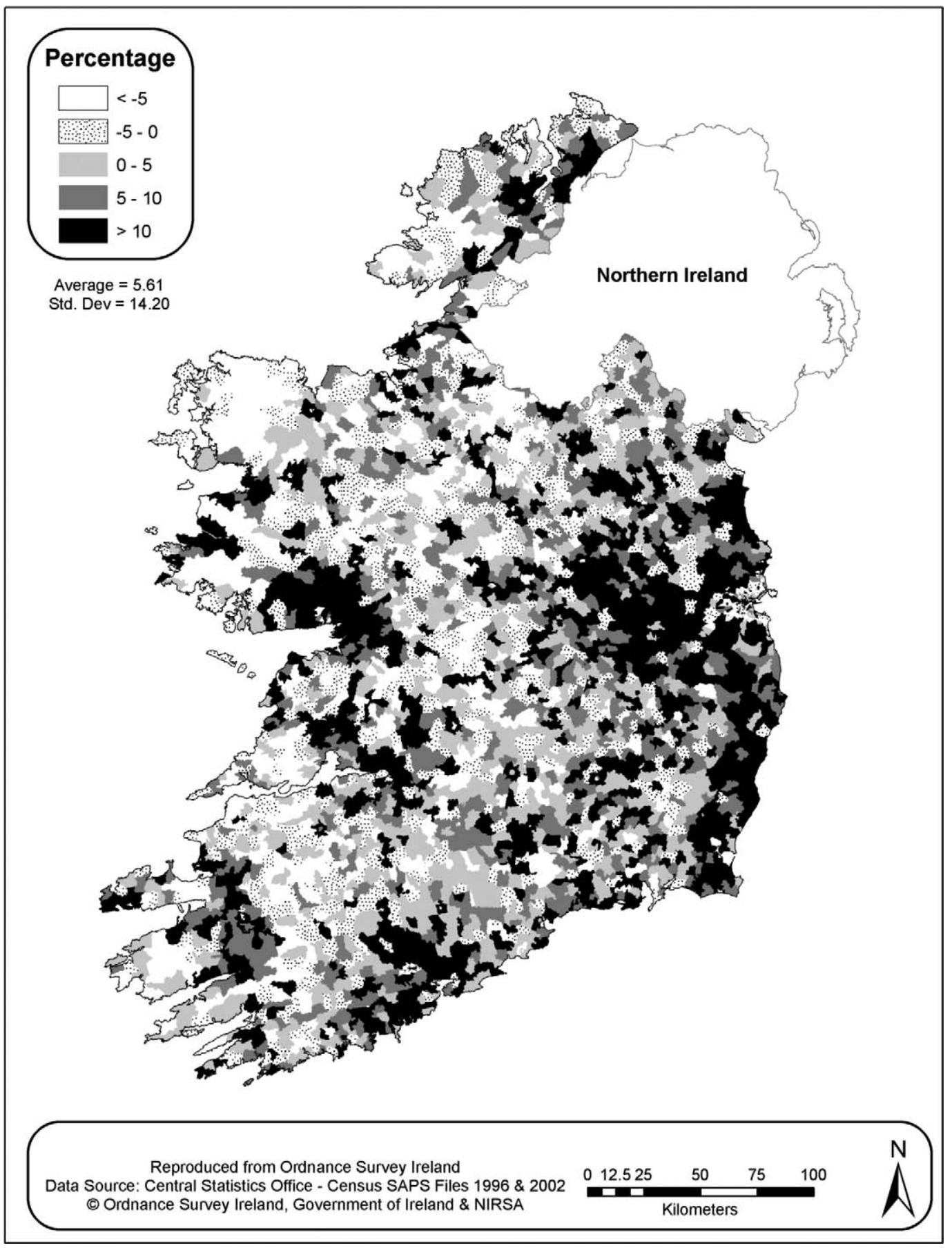

Figure 1 Is this image a map? Population change in Ireland, 1996-2002 
multifarious, contingent and relational ways. Second, we believe that it allows us a fresh perspective on the epistemological bases of cartography - how mapping and cartographic research is undertaken. Third, it 'denaturalizes and deprofessionalizes cartography' (Pickles, 2004: 17) by recasting cartography as a broad set of spatial practices, including gestural and performative mappings such as Aboriginal songlines, along with sketch maps, countermaps, and participatory mapping, moving it beyond a narrowly defined conception of mapmaking. (This is not to denigrate the work of professional cartographers, but to recognize that they work with a narrowly defined set of practices that are simply a subset of all potential mappings.) As such, it provides a way to think critically about the practices of cartography and not simply the end product (the socalled map). Fourth, it provides a means to examine the effects of mapping without reducing such analysis to theories of power, instead positioning maps as practices that have diverse effects within multiple and shifting contexts. Fifth, it provides a theoretical space in which 'those who research mapping as a practical form of applied knowledge, and those that seek to critique the map and mapping process' can meet, something that Perkins (2003: 341) feels is unlikely to happen as things stand. Perkins (2003: 342) makes this claim because he feels 'addressing how maps work . . . involves asking different questions to those that relate to power of the medium' - one set of questions being technical, the other ideological. We do not think that this is the case - both are questions concerning practice.

\section{Maps as practice-always mapping}

[a map ] is like the word when it is spoken, that is when it is caught in the ambiguity of an actualization, transformed into a term dependent upon many conventions, situated as the act of a present (or of a time), and modified by the transformations caused by successive contexts. (de Certeau, 1984: 117)

[a] tool is not just a thing with pre-given attributes frozen in time - but a thing becomes a tool in practice, for someone, when connected to some particular activity... The tool emerges in situ. (Star and Ruhleder, 1996: 112; our emphasis)

Brown and Laurier (2005) note that people are never simply mappers, but rather mapping is part of finding a solution to a wider problem. We think conceptualizing mapping as a set of practices aimed at solving spatial problems is highly productive. In this section we demonstrate this idea by thinking through different ways in which mapping solves spatial problems, using a set of examples. While these examples are illustrative in nature, we believe that they are not extreme or exceptional and are representative of the actual, material practices of mapping (and are based on our extensive experience of undertaking, observing and teaching such practices). We explain how mapping practices work in a theoretical and technical sense in the following section.

\section{Vignette 1}

John Doe has been given the task by a government department of reporting on the distribution of population change in Ireland between the 1996 and 2002 census. ${ }^{2}$ There are several potential solutions to this problem, such as producing statistical tables, figures or narrative description, each of which consists of a set of technical practices which can be used to complete the task. Given the spatial nature of the problem, producing what is commonly understood to be a map provides one viable solution. John's task as a cartographer is to construct a spatial representation using available data that conform to agreed standards and conventions and which effectively communicates the pattern of population change.

Starting from a position of having specialized tools (scientific instruments or software) and resources (boundary and attribute data, previously mapped information), and a degree of knowledge, experience and skills, John works to create a map. The map thus emerges through a set of iterative and citational 
practices - of employing certain techniques that build on and cite previous plottings or previous work (other spatial representations) or cartographic ur-forms (standardized forms of representation). This process is choreographed to a certain degree, shaped by the scientific culture of conventions, standards, rules, techniques, philosophy (its ontic knowledge), and so on, but is not determined and essential. Rather, instead of there being a teleological inevitability in how the map is constructed and or how the final product will look, the map is contingent and relational in its production through the decisions made by John with respect to what attributes are mapped, their classification, the scale, the orientation, the colour scheme, labelling, intended message, and so on, and the fact that the construction is enacted through affective, reflexive, habitual practices that remain outside cognitive reflection. Important here is the idea of play - of 'playing' with the possibilities of how the map will become, how it will be remade by its future makers - and of arbitrariness, of unconscious and affective design. John thus experiments with different colour schemes, different forms of classification, and differing scales to map the same data. Making maps then is inherently creative - it can be nothing else; and maps emerge in process.

For example, using mapping software the first stage might be to plot administrative boundaries. In doing so, decisions have to be made in terms of the administrative units to use (postcodes, enumeration areas, electoral divisions, counties, and so on), and the scale of the display. Next, these units need to be populated with data. To be able to do this the data need to allocated to a zone and sorted into categories that differentiate rates of population change. There are technical solutions to classification that can be performed using specialized algorithms. However, John still needs to determine which algorithm is most suitable given the structure of the data (eg, to use the default setting, choosing fixed intervals, mean standard deviation, percentiles, natural breaks and so on). These technical solutions are not fixed and essential in their practice but are also subject to play and precognitive judgement through the evaluation of different algorithms in order to determine which work 'best'. Alternatively, the classification can be devised through a manual, iterative playing with the data in terms of class boundaries, number of classes, and so on (which in fact was the case with Figure 1). Both cases, technical and manual, consist of practice (of running the algorithm or playing with the data), and these practices vary over time, by context, and across people. In terms of the visual display, a colour scheme needs to be devised. Similarly, there are technical solutions such as RGB, HLS or HVC models (see Robinson et al., 1995); ${ }^{3}$ in other cases the colour ramp is chosen by the cartographer. Finally, there are considerations concerning where the legend appears, whether labels appear on the map and where, and so on. While some of these practices seem prosaic, the procession of decisions and actions 'grows' the map. Each might seem banal or trivial, but their sum - the culmination of a set of practices - creates a spatial representation that John understands as a map (and believes that others will accept as a workable map based upon their knowledge and experience as to what constitutes a map).

When a spatial representation understood as a map is printed for inclusion in a policy document (see Figure 1), for example, we would argue that its creation is not complete - it is not ontologically secure as a map. Although it has the appearance of an immutable mobile - its knowledge and message fixed and portable because it can be read by anyone understanding how maps work - it remains mutable, remade every time it is employed. Like a street geometrically defined by urban planning, and created by urban planners, is transformed into place by walkers (de Certeau, 1984), a spatial representation created by cartographers (the coloured ink on the paper) is transformed into a map by individuals. As each walker experiences the street differently, each person engaging with 
a spatial representation beckons a different map into being. Each brings it into their own milieu, framed by their knowledge, skills and spatial experience, in this case of Ireland and Irish social history. For someone familiar with the geography of Ireland, their ability to remake the map in a way that allows them to articulate an analysis of the data is likely to be far superior to someone unfamiliar with the pattern of settlement (to know what the towns are, what county or local authority area they reside in, what their social and economic history is, their physical geography is, and so on). For someone who does not understand the concept of thematic mapping or classification schemes, again the map will be bought into being differently to people who do, who will ask different questions of the data and how it is displayed. While all people who understand the concept of a map beckon a map into being, there is variability in the ability of people to mobilize the representation and to solve particular problems. Moreover, the beckoning of the map generates a new, imaginative geography (an ordered, rationale, calculated geography) for each person, that of the spatial distribution of population change between the 1996 and 2002 census.

\section{Vignette 2}

Jane Doe is travelling from Manchester Piccadilly train station to the town hall. Ten minutes after she leaves the station she realizes she has taken a wrong turn somewhere and is now lost. Jane's problem is to determine where she is and then to compute a new route to her destination. One solution to this problem is consult the street map she is carrying in her bag. This consultation consists of more than reading an immutable mobile. Jane does not simply receive information from the map; rather she brings her own map into being in the moment through an engagement with the printed representation. In other words, the map is remade anew, emerging from the intersections between the knowledge, skills and experience of Jane to understand the language of cartographic representation and the spatial data within the representation. Jane makes the coloured ink on the page into a map through praxis; she works with the spatial representation to try and make sense of the world.

In Jane's case, making sense of the world is undertaken by making correspondences between the map and the streetscape. She looks at the map, then at the road, then back at the map. She tries to find objects such as street names or landmarks in the landscape that she can match to the map and vice versa. She locates the train station on the map, then traces her finger along the roads she thinks she might have taken, trying to locate herself. She then twists the map, changing its orientation and glances back at the street. She follows this by changing her own orientation turning to face a new direction, shifting her vision from map to street, gaining her bearings as she starts to make correspondence between her surroundings and the lines and symbols of the map. Jane is thus placing herself both in the material geography of the street and the map. In so doing, the map and the world gain legibility; they get remade in new ways. The process of mapping then alters Jane's imaginative geography of Manchester city centre and also the spatiality of the street in which she resides. Map and landscape are folded into each other to solve the problem of determining where she is. In other words, the map Jane beckons into being does not represent a space, or simply represent a space, it brings space into being (see Dodge and Kitchin, 2005). This beckoning is not determinate and teleological but is contingent and relational, embedded with the context of the moment (eg, anxiety, frustration) and as an aspect of other tasks (eg, attending a job interview, meeting friends, etc).

In addition, Jane's map can emerge in conjunction with other information, for example, a street index or a guide book or a note from a friend providing instructions of how to get between the station and the town hall (each of which is also beckoned into being in relation to each other). Here, the various media and Jane 
work together to link the spatial representation to the landscape and to traverse that landscape. Each adds value to the other, making the instructions on how to find the location more intelligible. Indeed, the friend's directions augment the other media. If the friend had drawn a route onto the professional street map then the map would have been rewritten in a novel way (what one might call a practice of 'overwriting'). The result would be a wholly new map combining embodied spatial knowledge with direct citations to pre-existing cartographic knowledge. Such sketch maps demonstrate the ability of people to unselfconsciously perform mappings that have sufficient accuracy and clarity to solve the problem of the moment. Rather than rely solely on the 'frozen' cartographic representations from a 'professionally' published source, such route mapping empowers individuals to describe their place in the world to others.

Once orientated Jane's next problem is to determine how to get to the town hall, to engage with map and the imagined and material geography to plot a new route and to then traverse this route. If Jane fails to place herself in either or both of the map or material geography then she is unable to traverse the city successfully. A solution might be to retrace her steps until she locates a recognizable landmark that allows her to solve the problem at that location. Another is to ask a passer-by for help. The passer-by might choose to ignore the map and give verbal directions to the town hall based on local knowledge. Alternatively (s)he might engage with the spatial representation in partnership with Jane. As Brown and Laurier (2005) demonstrate, maps are often beckoned into being collectively as shared social and cultural practices. Through collaboration Jane and the passer-by each beckon their own map into existence based on their experiences, knowledges and skills, with the conversation and practices of pointing, tracing, sharing views of the street, and so on, reshaping each map. Through this process Jane's map potentially gains depth and clarity and becomes easier to interpret (assuming the passer-by has competence to be able to help). In this sense, Jane's map is a 'collaborative manufacture' (Crang, 1994: 686), as is the space they beckon into being (see Dodge and Kitchin, 2004; 2005). Similarly, the spatial representation of population change becomes a collaboratively manufactured set of maps (each different for each participant) through discussion in a workshop, with the discussion reframing each participant's understanding of population change in Ireland, or more broadly simply the geography of Ireland.

\section{An ontogenetic understanding of maps}

From our examples we would argue that maps emerge in process through a diverse set of practices. Given that practices are an ongoing series of events, it follows that maps are constantly in a state of becoming; they are ontogenetic (emergent) in nature. Maps have no ontological security, they are of-themoment; transitory, fleeting, contingent, relational and context-dependent. They are never fully formed and their work is never complete. Maps are profitably theorized, not as mirrors of nature (as objective and essential truths) or as socially constructed representations, but as emergent. In this section we want to start to think through how maps emerge through practices drawing on the concepts of transduction and technicity; to provide a starting point for conceptually framing the process by which John and Jane begin to solve their relational problems.

According to Adrian Mackenzie (2003: 10) 'transduction is a kind of operation, in which a particular domain undergoes a certain kind of ontogenetic modulation. Through this modulation in-formation or individuation occurs. That is, transduction involves a domain taking-on-form, sometimes repeatedly' (his emphasis). Simondon (1992: 313) explains ' $\mathrm{t}$ ] he simplest image of the transductive process is furnished if one thinks of a crystal, beginning as a tiny seed, which grows and extends itself in all directions in its 
mother-water. Each layer of molecules that has already been constituted serves as the structuring basis for the layer that is being formed next, and the result is amplify-ing reticular structure'. In other words, the crystal grows through individuations, that cite previous individuations, to transduce elements into a crystal. Using this idea, if we think of John creating a map of population change, we can say that the plotting of lines, colours and so on consists of a series of individuations that transduces the blank page into a map, with each individuation citing previous plottings.

Transduction occurs because we are endlessly confronted with sets of relational problems - practices in effect aim to solve these problems (Mackenzie, 2002). In the case of mapping, those problems include metaproblems such as the production of maps or finding one's way, that in themselves are made up of hundreds of smaller problems such as where to place a label, what colour scheme to use, or how to orientate or make correspondence between map and territory. The solving of problems is always partial, opening up new problems (eg, the plotting of one line leads to the plotting of the next, and so on), and contextual (embedded within standards, conventions, received wisdom, personal preferences, direction by others, and so on). In this sense, transduction is the means by which a 'domain structures itself as a partial, incomplete solution to a relational problem' (Mackenzie, 2003: 10). In the examples above, the meta-problem for John is one of providing information with respect to population change in Ireland in a meaningful form that can be used by the contracting party in a policy document. This document in itself has transductive effects, alternatively modulating how the world is understood, and this understanding can then be used to enact policy initiatives and to transduce material geographies. The meta-problems for Jane are to locate herself with respect to map and location, and then to make her way to the town hall. Similarly, both imagined and material geographies are alternatively modulated. Without the map the problem getting from $A$ to $B$ might not be solved, or will be solved less efficiently or in a more costly manner.

As these relational problems make clear, maps are the product of transduction and they enable further transductions in other places and times; they are always in the process of mapping; of solving relational problems such as how best to present spatial information, how to understand a spatial distribution, how to find one's way. Here, we want to make it clear that we are not drawing a distinction between what traditionally has been divided into map-making and map use. Instead, to us all engagement with 'maps' are emergent - all maps are beckoned into being to solve relational problems; all are (re)mappings - the (re)deployment of spatial knowledges and practices. And all emergence is contextual and a mix of creative, reflexive, playful, affective and habitual practices, affected by the knowledge, experience and skill of the individual to perform mappings and apply them in the world. Conceiving of mapping in this way reveals the mutability of maps; that they are remade as opposed to mismade, misused or misread.

Mapping works because its set of practices has been learnt by people, ${ }^{4}$ and because maps are the product of technicity (made by tools) and they possess technicity (they are a tool themselves). Technicity refers to the extent to which technologies mediate, supplement, and augment collective life; the unfolding or evolutive power of technologies to make things happen in conjunction with people (Mackenzie, 2002). For example, mapping practices used to produce a spatial representation understood as a map by its creator are the product of cartographic instruments (pens, paper, rulers, software packages, etc) used in conjunction with people, where the outcome is co-dependent on both instruments and individual, and embedded within a particularized context. A spatial representation can be said to possess technicity when it 
is used by a person to solve relational problems; to alternatively modulate (transduce) activity and space. The solution arises from the conjunction of person and representation; they are produced through, or folded into, each other in complex ways. Maps thus should be understood 'processually ... as events rather than objects, as contingent the whole way down', 'as networks of socialmaterial interactions rather than simply reflections of human capacities or innately alien objects' (Mackenzie, 2003: 4, 8). Cartography as a profession is thus repositioned as a processual, ${ }^{5}$ as opposed to representational, science.

From this perspective, the important question is not is not what a map is (a spatial representation or performance), nor what a map does (communicates spatial information), but how the map emerges through contingent, relational, context-embedded practices to solve relation problems (their ability to make a difference to the world); to move from essentialist and constructivist cartography to what we term emergent cartography.

Epistemologically, what this means is that the science of cartography (how maps are produced) and critical analysis of cartography (the history and politics of cartography) are both positioned as processual in nature. Rather than one asking technical questions and the other ideological, both come to focus on how maps emerge through practices; how they come to be in the world. With respect to both, as Brown and Laurier (2005: 23, original emphasis) note, this calls for a radical shift in approach from 'imagined scenarios, controlled experiments or retrospective accounts' to examine how maps emerge as solutions to relational problems; to make sense of the 'unfolding action' of mapping. As such, cartographic research becomes refocused as a science of practices, not representations; on how a map is produced, how mapping is contextually co-constituted (within individual, collective and institutional frameworks), how maps are made to do work in the world, how the craft of cartographers and the lexicon they develop and use influence how maps are (re)made, how this work varies between people and the relational problems being solved, how maps gain the status of immutable mobiles and how this varies, and has varied, over time and space. Within this conceptual view, technical questions (ontic knowledge) concerning such things as accuracy and standards, remain an important focus of study, but are appreciated to be contingent, relational and context-dependent; that addressing technical questions is in itself a process of seeking to solve a set of relational problems. In other words, the focus of attention shifts to the relationship between cartographer, individuals, and a potential solution, and how mapping is employed to solve diverse and contextdependent problems (eg, how John produced a map of population change and Jane produced a map - using a published spatial representation - to get from one location to another), rather than a single map being viewed as a universal and essential solution to a range of questions (that there can be a 'best' or 'most accurate' map that all people understand and use in the same way to address a range of problems). This is, we believe, a subtle but important distinction as it recognizes a fundamental shift in conceptualizing the foundational knowledge underpinning cartography, and reconfigures the epistemology appropriately, without necessarily fundamentally altering many of the key technical questions at a technical level (but clearly at a philosophical level) that professional cartographers are interested in, while also opening up a set of wider issues and concerns that we believe deserves wider attention.

\section{Conclusion}

In this paper, we have examined in depth the ontological status of maps. Like Crampton (2003) and Pickles (2004) we agree that there is a need to rethink the philosophical bases of cartography, moving beyond ontic knowledge to construct new ontologies. Unlike Crampton and Pickles, however, we have questioned the ontological security of maps, 
instead arguing that maps are ontogenetic in nature. That is, maps are never fully formed and their work is never complete. Maps are of-the-moment, beckoned into being through practices; they are always mapping. From this perspective maps are fleeting, contingent, relational and context-dependent, emerging through transductive processes to solve relational problems. This theoretical turn has led us to suggest that cartography is processual, not representational, in nature. Rather than cartography being narrowly understood as the scientific pursuit of how best to represent the spaces of the world (focused on issues such as form and accuracy), cartography becomes understood as the pursuit of representational solutions (not necessarily pictorial) to solve relational, spatial problems. In so doing, cartography shifts from being ontical in status, wherein the ontological assumptions about how the world can be known and measured are implicitly secure, to an ontological project that questions more fully the work maps do in the world. This, for us, goes some way towards resolving Perkins' (2003) dilemma, providing a theoretical space in which to examine the technical and ideological aspects of cartography, and the full range of mapping practices including professional cartography, countermappings, participatory mapping, and performative mappings - all are necessarily selective, contingent and contextual mappings to solve relational, spatial problems.

Such a turn also clearly has epistemological implications with regards cartographic research and work, refocusing attention across the broad spectrum of cartography (practioners, technicians, historians, critical theorists, map 'users') on understanding mapping practices - how maps are (re)made in diverse ways (technically, socially, politically) by people within particular contexts and cultures as solutions to relational problems. Examining these practices can be undertaken in multiple ways (ethnographies, participant observation, technical measurement), as long as they are sensitive to capturing and distilling the unfolding and contextual nature of mapping. Here, there is an attempt to observe and acknowledge what cartographers do (undertake contextual science) - not what they say they do (undertake objective science) - and how people bring maps into being to solve relational problems in ways that extend beyond a naive understanding of map use (ie, collaboratively, in relation to places and other sources of knowledge, within context, etc). For professional cartographers this means taking seriously the conscious and unconscious decisions they make, the way creating a map unfolds in citational, habitual, reflexive and playful ways; and the diverse and context-dependent ways in which maps are brought into being by people as they live their lives (see Brown and Laurier, 2005). Such research, we believe, will open up productive ways of framing and reflexively refining cartographic theory and praxis, rather than simply critiquing the work of cartographers without providing epistemological suggestions (other than to acknowledge or reduce ideological bias as with much critical cartography as presently formulated).

While we have made a start in this paper to rethink cartography as a processual, emergent endeavour, there is clearly much more to be done both theoretically and empirically to extend and expand the ideas we have presented. We believe, however, that such an approach will be a productive exercise both ontologically and epistemologically, strengthening the philosophical tenets of cartographic research and production, and stimulating a rich vein of empirical, technical and historical research.

\section{Note}

1. As one of the referees of the paper suggested.

2. One of us was involved in such a project.

3. RGB is Red, Green and Blue system; HLS is Hue, Lightness and Saturation system; HVC is Hue, Value and Chroma system.

4. Pickles (2004: 60-61) explains: 'Maps work by naturalizing themselves by reproducing a particular sign system and at the same time treating that sign system as natural and given. But, 
map knowledge is never naïvely given. It has to be learned and the mapping codes and skills have to be culturally reproduced... The map opens a world to us through systems and codes of sedimented, acculturated knowledge.'

5. Our vision of processual cartography moves beyond Rundstrom's (1991) process cartography - which sees map-making as a subjective process embedded within a wider social context wherein the resultant map is immutable mobile - to recognize mapping as contingent, relational and continually emergent process. That is, is more profoundly poststructural in nature.

\section{References}

Antle, A. and Klickenberg, B. 1999: Shifting paradigms: from cartographic communication to scientific visualization. Geomatica 53, 149-55.

Brown, B. and Laurier, E. 2005: Maps and journeys: an ethnomethodological investigation. Cartographica 4, 17-33.

Crampton, J. 2003: The political mapping of cyberspace. Edinburgh: Edinburgh University Press.

Crang, P. 1994: It's showtime - on the workplace geographies of display in a restaurant in Southeast England. Environment and Planning D: Society and Space 12, 675-704.

de Certeau, M. 1984: The practice of everyday life. Berkeley, CA: University of California Press.

Dodge, M. and Kitchin, R. 2000: Exposing the 'second text' in maps of the Network Society. Journal of Computer Mediated Communication 5(4). Retrieved 13 February 2007 from http://jcmc.indiana.edu/ vol5/issue4/dodge_kitchin.htm

- 2004: Flying through code/space: the real virtuality of air travel. Environment and Planning $A 36$, 195-211.

-2005: Code and the transduction of space. Annals of the Association of American Geographers 95, 162-80.

Edney, M.H. 1993: Cartography without 'progress': reinterpreting the nature and historical development of mapmaking. Cartographica 30(2/3), 54-68.

Harley, J.B. 1989: Deconstructing the map. Cartographica 26, 1-20.

- 1992: Rereading the maps of Columbian encounters. Annals of the Association of American Geographers 82, 522-36.
Harris, L. and Harrower, M. 2006: Critical cartographies special issue. ACME: An International E-Journal for Critical Geographies 4(1). Retrieved 13 February 2007 from http:// www.acme-journal.org/Volume41.htm

Latour, B. 1989: Science in action. Cambridge, MA: Harvard University Press.

Livingstone, D.N. 1992: The geographical tradition: episodes in the history of a contested enterprise. Oxford: Blackwell.

- 2005: Science, text and space: thoughts on the geography of reading. Transactions of the Institute of British Geographers NS 30, 391-401.

MacEachren, A.M. 1995: How maps work: representation, visualization and design. New York: Guildford Press.

Mackenzie, A. 2002: Transductions: bodies and machines at speed. London: Continuum Press.

- 2003: Transduction: invention, innovation and collective life. Retrieved 13 February 2007 from http://www.lancs.ac.uk/staff/mackenza/papers/tran sduction.pdf

Monmonier, M. 1996: How to lie with maps. Chicago: University of Chicago Press.

Perkins, C. 2003: Cartography: mapping theory. Progress in Human Geography 27, 341-51.

Pickering, A. 1995: The mangle of practice: time, agency and science. Chicago: University of Chicago Press.

Pickles, J. 1995: Ground truth: the social implications of Geographic Information Systems. New York: Guildford.

- 2004: A history of spaces: cartographic reason, mapping and the geo-coded world. London: Routledge.

Robinson, A.H., Morrison, J.L., Muehrcke, P.C., Kimmerling, A.J. and Guptil, S.C. 1995: Elements of cartography (sixth edition). New York: Wiley.

Rundstrom, R.A. 1991: Mapping, postmodernism, indigenous people and the changing direction of North American cartography. Cartographica 28(2), 1-12.

Simondon, G. 1992: The genesis of the individual. In Crary, J. and Kwinter, S., editors, Incorporations 6, New York: Zone Books, 296-319.

Star, S.L. and Ruhleder, K. 1996: Steps towards an ecology of infrastructure: design and access for large information spaces. Information Systems Research 7, 111-34.

Wood, D. 1992: The power of maps. New York: Guilford Press.

- 1993: The fine line between mapping and mapmaking. Cartographica 30(4), 50-60. 